\title{
On the Current Situation of Online Teaching Offered by Some Universities in Sichuan to Their International Students During the Pandemic
}

\author{
Chunyao $\mathrm{Ou}^{1}$, Liping $\mathrm{Xia}^{2, *}$ \\ ${ }^{1}$ School of Public Administration, Sichuan University, Chengdu, China \\ ${ }^{2}$ College of International Studies, Sichuan University, Chengdu, China \\ *Corresponding author. Email: lipingxia@netease.com
}

\begin{abstract}
This study investigated the online teaching of some Chinese universities for their international students during the pandemic. The results of the questionnaire survey show that there are some problems existing in the online teaching such as students' weak online learning ability, inadequate interaction between teachers and students, teachers' insufficient online teaching ability, pandemic-induced stress affecting learning effect, etc. In the post epidemic era, in order to further improve the quality of online teaching for international students, colleges and universities need to strengthen the cultivation of students' autonomous learning ability, increase teachers' online teaching competence, and enhance the construction of online teaching system.
\end{abstract}

Keywords: Pandemic, International students, Online teaching, Post epidemic era.

\section{疫情背景下四川高校来华留学生线上教学现状探析}

\author{
欧春瑶 ${ }^{1}$, 夏网萍 $2, *$
}

\begin{abstract}
1 四川大学公共管理学院, 成都, 中国
2 四川大学出国留学预备学院, 成都, 中国

*通讯作者. 由箱: lipingxia@netease.com
\end{abstract}

\section{中文摘要}

本研究通过问卷调查了解疫情背景下高校来华留学生线上教学情况。问卷调查结果显示, 疫情期间来华留学生 线上教学存在学生在线学习能力弱、师生及生生之间互动不够、教师线上教学胜任力不足、学生心理负担影响 学习效果等问题。后疫情时代, 为进一步提高来华留学生线上教学的质量, 高校需加强来华生自主学习能力培 养，提升教师线上教学胜任力，完善线上教学体系建设。

关键词: 疫情，来华留学生，线上教学，后疫情时代

\section{1. 引言}

2020年，新型冠状病毒席卷全球，worldometers实 时数据统计：截至2021年3月8日，全球新冠肺炎感染 者共 $117,509,787$ 人, 累计死亡病例达 $2,606,789$ 例。突
发性灾难下, 留学事业遭受剧烈冲击。疫情严重期间, 很多国家不建议留学生返校, 课程教学改为线上进行。 我国的来华留学生教育亦然。目前很多高校的来华留 学生课程仍采取线上教学方式进行。本文通过问卷调 查, 了解、分析来华留学生线上教学现状，以期为后 
疫情时代高校来华留学生线上教学质量的进一步提 升提供参考建议。

\section{2. 研究对象和方法}

基于样本的可及性, 本研究通过问卷星平台、微 信群等方式对3所四川高校的部分来华留学生随机发 送自编问卷，收集信息。

自编问卷主要包括来华留学生人口统计学数据, 教学模式、班级规模、授课时长等线上教学基本情况, 影响线上教学成效的因素, 线上教学遇到的问题, 对 线上教学提出改进意见等内容, 题目总量 22 个。其中, 影响线上教学成效的因素涵盖学生在线学习能力、教 师在线教学能力、线上教学硬件支持、在线课堂管理、 疫情下学生心理等五个方面。问卷回收后, 进行SPSS 分析得出信度系数为 $0.962, \mathrm{KMO}$ 值为 0.799 , 说明数 据可信且有效。因此, 该问卷可以用于本研究分析。

\section{3. 调查结果与分析}

\section{1. 线上教学基本情况}

回收的76份有效样本中, 汉语专业留学生占比 $18.75 \%$, 除汉语之外的人文社科专业学生占比 $25 \%$, 理工科专业留学生占比 $26.25 \%$, 医科专业学生占比 $30 \%, 67.53 \%$ 的学生日均接受网络教学时长为 $1-3$ 个小 时, $19.48 \%$ 的学生日均接受网络教学时长为 $3-6$ 个小 时, 日均接受网络教学时长大于 6 小时的占 $7.79 \%$, 小 于1 小时的只占 $5.19 \%$ 。 $45.45 \%$ 的学生接受网课数量为 1-3科, 3-6科的占 $27.27 \%$, 另有 $27.27 \%$ 的学生网课数 量超过了 6科。网课班级规模基本在30-50人左右。课 堂上, 教师多采用汉语或英语、或汉英双语授课。

\section{2. 线上教学形式}

受访结果表明, 线上教学形式多样, 有直播、录 播、文字+音频等, 但直播模式使用频率最高, 频次 总分 323 分, 而文字+音频为 254 分, 录播为 225 分。总 的来说, 教师仍习惯使用类似线下教学的授课方式。 问卷显示, 常用的线上教学平台为钉钉、腾讯课堂、 QQ直播, 分别占 $29.87 \% 、 31.17 \% 、 11.69 \%$ 。

\section{3. 线上教学的成效}

$61.04 \%$ 的受访者表示线上教学效果不如传统线下 教学, $24.68 \%$ 学生反馈线上教学和传统线下教学效一 样; 仅有 $14.29 \%$ 学生认为线上教学比传统线下教学效 果好。可见, 于大多数学生而言, 线上学习效果不如 线下。

\section{4. 影响线上教学成效的主要因素}

本文采用李夸特量表对受访者回答结果进行计分, 算出影响线上教学成效各因素的总分, 总分越高代表 学生认为该因素越重要, 排名前5的因素整理在表1中。
结果显示: 多数学生认为网络速度及稳定性是开展线 上教学时最重要的因素; 作为课堂主导者, 教师对于 教学的态度、精力投入、策略等也十分重要。同时, 作为学习主体, 学生需要积极参与课堂, 自觉投入学 习。

表 1. 影响线上教学成效的主要因素

\begin{tabular}{|c|c|c|c|c|}
\hline 名称 & 选项 & 频次 & $\begin{array}{l}\text { 分 } \\
\text { 值 }\end{array}$ & \begin{tabular}{l|} 
总 \\
分
\end{tabular} \\
\hline \multirow{5}{*}{ 网络速度及稳定性 } & 完全同意 & 50 & 5 & \multirow[t]{5}{*}{345} \\
\hline & 同意 & 19 & 4 & \\
\hline & 一般 & 4 & 3 & \\
\hline & 不同意 & 3 & 2 & \\
\hline & 完全不同意 & 1 & 1 & \\
\hline \multirow{5}{*}{$\begin{array}{c}\text { 教师对教学的态度 } \\
\text { 及精力投入 }\end{array}$} & 完全同意 & 36 & 5 & \multirow[t]{5}{*}{329} \\
\hline & 同意 & 31 & 4 & \\
\hline & 一般 & 8 & 3 & \\
\hline & 不同意 & 0 & 2 & \\
\hline & 完全不同意 & 1 & 1 & \\
\hline \multirow{5}{*}{$\begin{array}{l}\text { 教师的教学策略及 } \\
\text { 讲授 (演示) 方法 }\end{array}$} & 完全同意 & 36 & 5 & \multirow[t]{5}{*}{329} \\
\hline & 同意 & 33 & 4 & \\
\hline & 一般 & 4 & 3 & \\
\hline & 不同意 & 2 & 2 & \\
\hline & 完全不同意 & 1 & 1 & \\
\hline \multirow[t]{5}{*}{ 学生自主学习能力 } & 完全同意 & 28 & 5 & \multirow[t]{5}{*}{322} \\
\hline & 同意 & 38 & 4 & \\
\hline & 一般 & 10 & 3 & \\
\hline & 不同意 & 0 & 2 & \\
\hline & 完全不同意 & 0 & 1 & \\
\hline \multirow[t]{5}{*}{ 学生积极参与 } & 完全同意 & 33 & 5 & \multirow[t]{5}{*}{320} \\
\hline & 同意 & 29 & 4 & \\
\hline & 一般 & 12 & 3 & \\
\hline & 不同意 & 1 & 2 & \\
\hline & 完全不同意 & 1 & 1 & \\
\hline
\end{tabular}

\section{5. 疫情期间学生心理状况}

问卷表明： $55.26 \%$ 的受访者网课期间因无法与同 学互动进行社交而感到孤独; 53.94\%的学生时常因疫 情和疫情有关的事感到紧张焦虑; 52.63\%的受访者对 于现在的生活状况感到无所适从; 50\%的留学生曾因 无法适应线上教学而产生沮丧情绪; $51.31 \%$ 的学生担 心疫情使自己延迟毕业。可见, 疫情期间, 来华留学 生或多或少出现心理问题。

\section{4. 疫情期间线上教学存在的问题分析}

网课期间, 来华留学生总体对教师线上教学的态 度比较满意, 但也反映出一些问题。 


\section{1. 留学生自主学习能力较弱}

调查数据显示: $48.68 \%$ 的受访者认为自己的自主 学习能力弱, 无法适应新的学习情况; $57.89 \%$ 的学生 出现上课注意力涣散情况, $47.37 \%$ 的学生表示自律性 差, 难以认真听课、完成作业。可见, 留学生自我控 制能力较弱, 自主学习能力不足。国内的留学生教育 由于受到传统教育的影响, 学生课堂主体地位体现不 够, 教师将加工后的知识传授给留学生, 学生很少主 动进行探究思考, 自主学习能力不能得到很好的锻炼。

另外, 网络课堂缺少学习氛围, 师生处于时空分 离状态, 缺少约束的学生更易出现注意力涣散、上课 偷懒等情况, 来华留学生群体的约束能力和学习主动 性较弱, 在线教学情况下这些问题更为突出。

\section{2. 师生、生生之间互动不够}

线上学习过程中, 虚拟空间带来的不真实感、交 流效率低下等因素影响师生、生生之间互动。调查显 示, 课堂参与度不够、课后缺乏与老师和同学沟通渠 道这两个选项总分领先于其他问题得分。互动不够可 能会产生以下问题:

一方面, 教学效果受到影响。线下教学过程中, 教师可就教学内容提出问题, 获得课堂反馈, 验证学 生掌握程度, 及时调整教学策略。然而, 直于时空的 分离, 教师难以在网络课堂上充分了解留学生知识掌 握程度。同时, 开展探究性合作学习难度加大, 学生 在动态教学中实现深度学习的可能性降低。

另一方面, 留学生跨文化交际能力无法得到有效 培养。线下课堂上, 留学生可以在真实情境中, 经历 文化冲突, 提升自己的跨文化交流和适应能力。而在 线课堂上, 师生、生生互动不够, 留学生体验文化多 样性、与不同国家或地区学生进行合作交流的机会减 少。

\section{3. 教师线上教学胜任力不足}

$42.1 \%$ 的学生表示老师采取的教学策略不适应网 络课堂, $48.68 \%$ 的学生回答部分教学内容不适用线上 教学, $71.05 \%$ 受访者建议老师改变原有教学策略。可 见, 教师线上教学胜任能力存在一定问题。线上教学 胜任力指保证线上教学顺利进行所需的知识、技能、 能力和态度。疫情之前, 中国教育部已要求教师创建 自己的在线课程体系, 但体系建设仅停留在将课堂教 学材料转移到在线教学平台。许多教师线上教学经验 仍较缺乏, 他们在如何选择合适的教学工具和线上教 学策略, 根据网络特点和课程性质重新组织教学内容, 激发学生学习动机等方面还有待加强。

\section{4. 学生不良心理影响学习}

疫情下, 受到个人健康状况、亲人的健康状况、 感染疾病的不确定性等因素的影响, 人们易出现不良
心理; 加上社会互动大大减少, 如长期无法感受团体 互动, 其社会疏离感恐会增加, 影响心理健康。48.68\% 的受访者表示担忧与焦虑的情绪影响上课的效果; 48.78\%的学生担心疫情会致使其延迟毕业; $53.16 \%$ 受 访者担心疫情会引发经济衰退, 就业机会减少。种种 焦虑、担忧、沮丧等心理状态, 对学习产生不利影响。

\section{5. 对策和建议}

虽然疫情期间线上教学过程中出现的问题带有应 急状态下的特殊性, 但加强对问题的分析与对策研究, 对后疫情时代的线上教学将有启发意义。立足后疫情 时代, 高校可从以下几方面入手, 保证来华留学生线 上教学质量。

\section{1. 培养学生自主学习意识, 提高自主学习能 力}

线上教学有时空分离、学习氛围淡薄等特征, 因 而对学生自主学习能力提出了更高的要求。因此, 教 师在教学过程中注重培养来华生的自主学习意识, 引 导明晰自主学习能力的重要性, 向学生传授自主学习 策略, 培养学生根据不同学习内容选择合适策略的能 力。在教学过程中, 教师转变角色定位, 从传统课堂 主导者、规划者转变为参与者、支持者, 给予学生更 多练习机会, 帮助其自主学习、自主构建知识体系。

同时, 通过帮助学生明确学习目标激发学习动机 和自主学习动力。例如, 教师可以任务清单的方式将 课程内容的知识结构、重点、难点以及需要深入思考 讨论的问题等发给学生并将之纳入考核范围。

\section{2. 多渠道增加师生互动、生生互动}

课堂上，创设具有一定复杂性、综合性和挑战性 的真实生活情景与知识情景, 设置有开放性、探究性、 思维深度的学习问题, 组织学生进行发言讨论。同时, 教师以平等的身份加入讨论, 引导学生将讨论聚集于 思维深刻、富有价值的话题中, 避免讨论滑向无意义 交谈。

课后开设三个渠道增加互动。第一、布置需要协 作才能完成的小组作业。分组时, 有意识地将不同国 别和文化背景的学生放入同一小组, 学生必须主动与 不同背景的伙伴进行协作, 培养合作交流能力, 提升 自己的跨文化能力。第二、建立日常交流小组, 学生 就学习、生活、抗疫健康知识等话题进行沟通与互动, 感受思维碰撞和文化交流, 纾解疫情带来的孤独感。 第三、教师多与学生交流, 为学生答疑解惑, 对学习 有困难或出现焦虑情绪的学生及时给予帮助和关怀。 


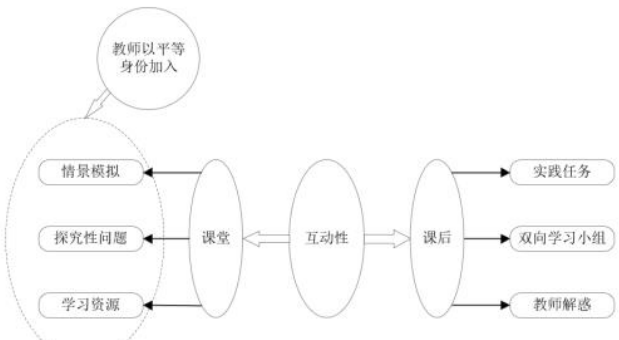

图 1 多渠道互动图

\section{3. 加强线上教学培训和团队建设，提升教师 在线教学胜任力}

加强教师在线能力培训, 帮助教师深入了解在线 教学的理念、方法和手段, 掌握在线教学工具使用技 巧, 熟练运用现代信息技术手段, 做好线上教学、互 动、答疑、作业及学习评价等环节, 保证教学质量。

建立教师线上教学沟通平台, 根据课程及授课对 象搭建教师团队学习共同体，开展不定期交流，探讨 来华留学生这一特殊受教育群体的特点、学习需求及 教学方法, 分享线上教学资源和教学经验, 分享学生 动态信息。在相互交流、相互学习中获得启发, 进一 步提升在线教学能力。

\section{4. 建立科学完善的线上教学体系, 保证教学 质量}

疫情常态化下, 来华留学生线上教学不再是高校 为应对突发状况而采取的短期行为, 而是一场长期的 教学革命。高校需建立一套符合线上教学模式的教学 体系, 从教学内容、教学资源、教学模式、教学策略、 教学督导评价、到学生成绩评价, 建立一套完整的体 系, 并在实践中不断改进、不断完善, 确保线上教学 工作顺利进行，促进线上教学质量不断提高。

\section{REFERENCES}

[1] COVID-19 CORONAVIRUS PANDEMIC. https://www.worldometers.info/coronavirus/,20213-8.

[2] DanWang, Li -Lin, Xiao-guang Ji. Research on the education and training model of foreign students in China[J]. Higher Education Exploration, 2016(S1): 160-161.

[3] Dong-hong Dai. Research on innovative training model of foreign students studying for academic degrees in China_-Based on the characteristics of group learning[J]. Guangxi Social Sciences, 2017(08):218-220.

[4] Wang Y, Wang Y, D Stein, et al. Examining Chinese beginning online instructors' competencies in teaching online based on the Activity theory $[\mathrm{J}]$. Journal of Computers in Education, 2019, 6(3).

[5] Xiao, Xiao. Supporting the construction of College Teachers Information-based teaching ability with online open course system. China University Teaching, 2018, 000(009):70-73.

[6] Cava M A, Fay K E , Beanlands H J, et al. The experience of quarantine for individuals affected by SARS in Toronto[J]. Public Health Nursing, 2005, 22(5):398-406. 